\title{
Entropy, Substitution and Sustainable Economic Growth
}

\author{
Yanying Chen (Corresponding author) \\ School of Economics, Dalian University of Technology \\ 2 Ling Gong Road, Dalian 116024, China \\ Tel: +86-411-8470-8559Ｅ-mail: yychen@dlut.edu.cn \\ Chunying Li \\ School of Economics, Dalian University of Technology \\ 2 Ling Gong Road, Dalian 116024, China \\ Tel: +86-411-8470-8559Ｅ-mail: chunchunli520@163.com
}

Received: February 25, 2011 Accepted: May 6, 2011 doi:10.5430/rwe.v2n2p66

\begin{abstract}
In the debate over sustainable economic growth, two critical issues are elasticity of substitution and technical change. Due to entropy increasing law in MEI system, the elasticity of substitution between any two resources must decline to zero and the efficiency improvement of resources from technical change is also limited. Therefore, substitution and technical change can not sustain economic growth forever.
\end{abstract}

Keywords: Entropy, Sustainable economic growth, Elasticity of substitution, Resource, Technical change

\section{Introduction}

Sustainable development is the primary problem facing human society in the 21st century. As economic growth has long been a panacea to solve unemployment, population growth and equity issues for many countries, the controversy is centered on sustainability of economic growth (Jones, 1999; Cai, 2005, pp.34-37; Li, 2009, pp.32-35). The existing views about whether economic growth can be sustainable under resource constraints are attributed to two critical issues. Most economists define scarcity of resources in terms of opportunity cost, supporting that market price is an indicator of resource scarcity. When a resource becomes rare, a rise in price will induce the economic entity to use other relatively abundant resources, so economic growth can be sustainable. However, most ecologists understand resource scarcity from the physical stock's view, thinking there is no possibility for resource substitution. Economic growth would stop or even be worse when the stock of critical resources was completely consumed by human economic activities (Daly, 1996; Yu, 2006, pp.12-17).

From the economic point of view, the key difference between two critical issues mentioned above is the elasticity of substitution. The optimistic issue assumes the elasticity of substitution between factors should be large enough, at least equal to 1. For example, Stiglitz (1974, pp.123-137) built a model to prove feasibility of economic growth. One key assumption of his model was that elasticity of substitution between natural resources and capital was greater than 1 . In contrast, the pessimistic issue assumes the elasticity of substitution is small, and there is at least a resource whose substitution elasticity for others is less than 1 .

Technical change is another aspect related to sustainable economic growth. The current view reflects optimism as to whether technical change can provide the solution to serious and even persistent environmental issues (Herman and Claudia, 2005, pp.133-147; Tao, 2008, pp.16-19). Most mainstream economists agree that technical change can remove resource limits on economic growth. Technical change could change the elasticity of substitution, improve resource efficiency and mitigate resource scarcity in a long time (Loverjoy, 1996, pp.266-278; Smulders and de Nooij, 2003, pp.59-79). Pu Yongjian (2000) believed that the material stock of natural resources was limited and would gradually decrease with the human economic growth. However, he also believed technological advances would improve the economic contribution of resources, so the economic stock of natural resources would grow continuously and economic growth was sustainable. The research of Yang (2004, pp.40-43) supported that technical change was the driving force of modern economic growth. Without technical change, economic growth would heavily depend on the consumption of energy and resources, which would eventually lead to energy depletion. 
The related literatures that focus on entropy, substitution and economic growth in the framework of new growth theory have not yet formed a complete theoretical system. This paper, Based on existing studies, uses entropy increasing law in Material-Energy-Information (MEI) system to analyze how elasticity of substitution and technical change will affect sustainable economic growth. Our research shows the elasticity of substitution between any two resources must decrease because of entropy increasing law in MEI system, and the efficiency improvement of resources from technical change is also limited. Therefore, substitution and technical change can not sustain economic growth forever. Our findings will not only provide a new perspective for the research of economic growth theory, but also help us better understand the dynamic process of economic growth.

\section{Entropy Increasing Law in MEI System}

Human economic activities are inseparable from material, energy and information. Although mainstream economic growth theory is still divorced from the real material world, as a typical MEI system, the economic activities are bound to obey the basic laws of thermodynamics.

Entropy increasing law, also known as the second law of thermodynamics, describes a continuous and irrevocable qualitative degradation trend in the transformation process of material and energy. For example, if a house collapsed, the glass, steel and cement which formed the house had not gone away, but turned into useless powder-like particles or waste. Simply, entropy is invalidity. The only way to slow entropy is the maintenance and repair, by adding new substances to make up for the originally qualitative degradation. However, as the house must be rebuilt when it is weathering to a certain extent, the original function of the substance will be completely lost when the entropy increases to a certain extent, so we have to use other materials.

The use of energy follows the same laws. For example, if we burn a piece of coal, the energy is not destroyed, but disperses into the air with sulfur dioxide and other gases. Although the total energy conserve in the combustion process, part of energy turns into heat which we can't use, so the effective energy decreases. That's why the perpetual motion machine is impossible to exist in reality.

Dose entropy increasing law also exist in the use of information? One view, which is an important basis of the optimistic issue, supports information is a kind of public goods whose quality remain unchanged or increase in use, so information can overcome entropy increasing law to some extent. The increasing entropy of substance and energy can be offset by the decreasing entropy of information, so the total entropy is unchanged (Kozo, 1999). However, what is information? In essence, information is a new understanding of the attributes and characteristics of things. Information is important because it can make economic entities grasp better ways and means in economic activities. Information dissemination must rely on substance and energy. Communication instruments, publications and other means of information dissemination are inseparable from substance and energy. Therefore, information can't get rid of the increasing entropy. The view that information can overcome increasing entropy in the economic system just ignores substance and energy basis of information.

The entropy increasing law determines economic activities must be resource-intensive. Supply of resources will decline with increasing output unless resources can be renewable. Georgesu-Roegan (1972) divided factor inputs of economic activities into energy resources and structural resources, and the former provided power while the latter formed buildings and equipments. Being consistent with mainstream theory of economic growth, this paper assumes all economic output only come from energy, capital and labor. The output has a decreasing trend because of entropy increasing law. The way to maintain output growth is to increase investment, which will affect technical change and substitution between factors, thus will affect the sustainability of economic growth.

\section{Entropy and Elasticity of Substitution}

Elasticity of substitution measures the degree of substitution between two factor inputs. Supposing there are only two production factors $\mathrm{A}$ and $\mathrm{B}$, and the output remains unchanged, if the relative price of A with respect to B increases by $1 \%$, then the relative inputs of $B$ with respect to A will correspondingly increase by $1 \%$, so the elasticity of substitution between $\mathrm{A}$ and $\mathrm{B}$ is 1 . That is what the Cobb-Douglas production function describes. If the relative inputs of $\mathrm{B}$ with respect to $\mathrm{A}$ is larger than $1 \%$, then the elasticity of substitution is greater than 1 ; otherwise it is less than 1 .

In essence, the elasticity of substitution is determined by the rate of technical substitution. If the rate of technical substitution is zero, keeping the amount of factor A unchanged while increasing the amount of B will not increase the output. Therefore, when the rate of technical substitution is zero, the elasticity of substitution between factors will also equal to zero.

\subsection{Capital and Labor}


We will first study substitution between capital and labor before explaining the influence of entropy on substitution elasticity. Cobb-Douglas production function that includes capital and labor is as follows:

$Q=A \cdot\left(L^{a} \cdot K^{b}\right), \quad a+b=1$

Where $\mathrm{A}$, a and $\mathrm{b}$ are parameters, $\mathrm{Q}$ is aggregate output, $\mathrm{L}$ is supply of labor, and $\mathrm{K}$ is supply of capital. In order to produce $\mathrm{Q}$, the quality of capital and labor must remain unchanged in production process. However, due to the increasing entropy, the quality of capital and labor can't be constant from the beginning to the end. For instance, we must maintain and repair the car annually to keep it at the best state. The capital also needs maintenance. If not, its output will decrease. So the maintenance of capital requires resources. Labor also needs resources in the same way.

Since in the current studies it's assumed the factors consumed by maintenance are low, CD production function always ignores maintenance for production factors, as do other production functions. If the production doesn't reach the production possibility frontier, the assumption of zero maintenance is closer to the real world. However, when the production moves along the possibility frontier to the corner point, we must distinguish inputs for maintenance from inputs for production. Figure 1 shows the isoquant curve of capital and labor. The line above the horizontal line is the entropy ratio line, which represents the required labor for maintenance of capital at each given capital level. If 100 units of capital are used in the production, the maintenance of these inputs needs 2 units of labor. Then the maintenance of 200 units of capital will require 4 units of labor, and so on. In a word, the amount of labor for maintenance will increase with the rising amount of newly-added capital.

To make up for quality degradation caused by entropy increase, the amount of labor inputs will rise with the increasing amount of capital inputs to maintain the required output in the process of substituting capital for labor. So the isoquant curve will move forward gradually to the entropy ratio line. This movement means the rate of technical substitution of capital for labor will eventually reduce to zero. At this point, the elasticity of substitution of capital for labor is zero.

When substituting labor for capital, the increasing amount of labor inputs also needs maintenance. When an economy entity tries to substitute labor for capital in a greater amount, each newly-added worker needs at least a certain amount of capital to enter process of production. That forms the lowest labor/capital ratio line in Figure 1. The isoquant curve moves gradually to the lowest labor /capital ratio line and the entropy ratio line at the same time, finally forming C-shaped. In the left top of the isoquant curve, the elasticity of substitution of labor for capital will also reduce to zero.

\subsection{Energy and Capital}

One view supports energy and capital are complement goods in the short term, but can substitute for each other in the long term (Apostolakis, 1990, pp.48-58). If substitution possibility really exists, we can produce more capital goods to reduce the dependence on energy. For instance, we can use two 6-engine trucks to replace a standard 8-engine truck, both of which have the same efficiency while energy that the former need will be less than that of the latter does. Although many supporters of sustainable economic growth have advocated we should increase the energy-saving capital investment to support economic growth, these complex capital equipments always have faster rate of increasing entropy, and the maintenance cost more energy. Therefore, the entropy ratio line in Figure 1 also exists in the process of substituting capital for energy. With the capital/energy ratio increasing, the isoquant curve will eventually converge to the entropy ratio line and the elasticity of substitution of capital for energy will reduce to zero.

Conversely, energy can also replace capital. Firms can increase the amount of energy and reduce the amount of capital in the long time. However, energy production, conversion and transport are all inseparable from capital. Capital investment must reach a minimum amount to make energy play a role in production. Therefore, the process of substituting energy for capital also faces the lowest rate line in Figure 1. With increasing energy in use, the isoquant curve will eventually converge to the lowest rate line and the elasticity of substitution of energy for capital will reduce to zero.

\subsection{Energy and Labor}

Energy can replace labor at the isoquant curve, vice versa. However, the increase in energy use will inevitably lead to increase in capital use as what we had explained above. In the effect of entropy increasing law, maintenance of capital consumes labor, so there is a minimum capital/labor ratio. That ratio is then converted into the corresponding minimum labor/energy ratio. With energy input increasing, the amount of capital investment will rise, and the maintenance of more capital requires more labor to make up for quality degradation. Above the isoquant curve of energy and labor, there is an entropy ratio line leaning upward to top right. With the isoquant curve moving gradually to that line, the elasticity of substitution of energy for labor will reduce to zero.

The maintenance of labor requires capital and the maintenance of capital requires energy. When substituting labor for energy, the isoquant curve will converge to the lowest labor/energy ratio line with the amount of labor inputs rising, and 
then the elasticity of substitution of labor for energy will eventually decline to zero.

It can be seen from the analysis that due to entropy increasing law, technical substitution rate between any two resources will tend to zero, and the elasticity of substitution will also inevitably decline to zero.

\section{Entropy and Technical Change}

If one resource can't be infinitely substituted by others, technical change at least can be a way to improve the efficiency of scarce resources. That's why the optimistic issue of sustainable economic growth is also a technical optimism. However, how technical change can improve resource efficiency is generally ignored in the existing research.

Due to the entropy increasing law, quality of substance and energy will inevitably decrease. The efficiency of any resource will be less than 1 . If the maximum efficiency of resources, determined by the entropy increasing law, is defined as the natural utilization efficiency, technical change can improve efficiency and save resources when the actual utilization efficiency is lower than the natural efficiency. Once the actual utilization efficiency has reached its natural efficiency, technological progress is unable further to improve the efficiency. Therefore, technical change can not infinitely improve the utilization efficiency of resources. In the long run, it's obviously unrealistic to overcome restrictions of key production factors like non-renewable energy on economic activities through new technologies.

Technical change is just an abstract term of economics. In reality, technical change performs as a series of specific forms like new equipment, new materials and new technologies, and its practicable method can't be separated from energy, capital and other resources. New technology can save one resource at the cost of greater consumption of other resources. Many studies show that since the industrial revolution the most significant feature of technical change is that human economic activities have turned to using non-renewable resources instead of renewable resources. As a double-edged sword, technical change can't fundamentally improve the efficiency of resources.

\section{Conclusion}

Economic growth is a common goal of all countries, which is often put in the first place among the governments' macro-control goals. This assumption clearly implies that economic growth should and can continue, but the results of this paper negate this assumption. Although economic growth has not yet reached the limit of resources at the present stage, it does not mean we can ignore the existence of the limit. Due to entropy increasing law, the elasticity of substitution between resources is bound to decline to zero, and technical change has only limited scope to improve efficiency. Therefore, substitution and technical change can not sustain economic growth forever.

Acceptance the existence of the limits of economic growth will help us re-examine the current process of economic growth. As a subsystem of the ecosystem, human economic growth can not exceed the size which the ecosystem can support. Only by shifting our goals from persuading economic growth to improving the quality of economic growth can we truly achieve sustainable development.

\section{References}

Apostolakis, B.E. (1990). Energy-capital substitutability. Energy Economics, 10, 48-58. http://dx.doi.org/10.1016/0140-9883(90)90007-3

Cai Fang. (2005). Changing pattern of economic growth and source of sustainability. Macroeconomics, 12, 34-37,41.

Daly, H.E. (1996). Beyond growth: the economics of sustainable development. Boston: Beacosn Press.

Georgescu-Roegen. (1972). The entropy law and the economic process. Cambridge, MA: Havard University Press.

Herman R. J., \& Vollebergh, Claudia Kemfert. (2005). The role of technological change for a sustainable development. Ecological Economics, 54, 133-147. http://dx.doi.org/ 10.1016/j.ecolecon.2004.12.025

Jones, Hywel G. (1999). An introduction to modern theories of economic growth. Beijing: The Commercial Press.

Kozo Mayumi. (1999). Bioeconomics and sustainability. Massachusetts: Edward Elgar Publishing.

Li Jinkai. (2009). Natural resources and economic growth: the understanding of mainstream growth theory. Economic Perspectives, 9, 32-35.

Lovejoy, D. (1996). Limits to growth? Science and Society, 60, 266-278.

$\mathrm{Pu}$ Yongjian. (2000). The industrial structure adjustment and industrial policy in the change of economic growth mode . Beijing :Huawen Publishing House.

Smulders S., \& de Nooij M. (2003). The Impact of Energy Conservation on Technology and Economic Growth. 
Resource and Energy Economics, 25, 59-79. http://dx.doi.org/10.1016/S0928-7655(02)00017-9

Stiglitz, J. (1974). Growth with exhaustible natural resources. Review of Economics Studies, 22, 123-137. http://dx.doi.org/10.2307/2296377

Tao Lei, Liu Chaoming, \& Chen Yan. (2008). Endogenous growth model under regenerative resources condition. Journal of Zhongnan University of Economics and Law, 1, 16-19.

Yang Honglin, Tian Lixin, \& Ding Zhanwen. (2004). Sustainable economic growth under restraint of energy. Systems Engineering, 3, 40-43.

Yu Bo, Li Yongliang, \& Chi Chunjie. (2006). Endogenous model with exhaustible energy, pollution abatement spending and sustainable growth induced. Journal of Management Sciences in China, 4, 12-17.

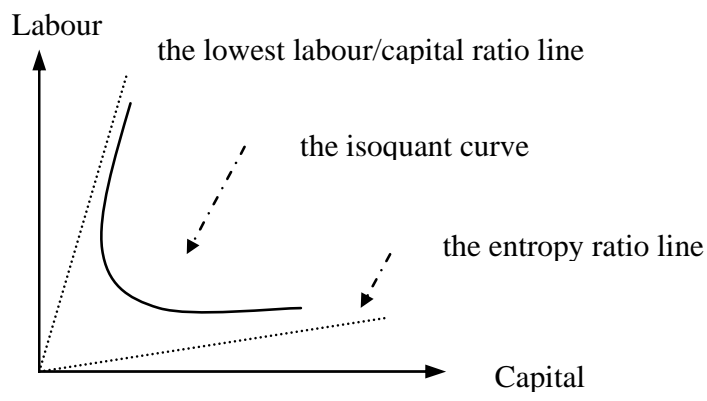

Figure. 1. The Influence of Entropy on Elasticity of Substitution 